\title{
Shining a light on burnout
}

\author{
Navjoyt Ladher clinical editor
}

The BMJ

Last week a photograph of a sign affixed to a faulty vending machine went viral on Twitter, for its perfect description of burnout: "The light inside has broken but I still work."1

Most doctors experience burnout at some point in their career, so the feeling will be familiar to many of us. But the situation is getting worse. Burnout rates among doctors are rising and reaching almost epidemic levels, say Jane Lemaire and Jean Wallace in an editorial (doi:10.1136/bmj.j3360), one of several articles this week to explore causes, symptoms, and solutions relating to this pressing problem.

Long hours, workforce gaps, rising demand, social care cuts, and a culture of blame all contribute to the pressures faced by doctors in the NHS, says David Oliver in his weekly column, with a fragile system "compounded by top-down target pressures and serial, politicised reorganisations" (doi:10.1136/bmj.j3604).

Against this backdrop of growing workplace stress it is easy to hark back to the good old days. Could the reintroduction of working patterns from years gone by help? This week's Head to Head debate asks whether doctors should work 24 hour shifts (doi:10.1136/bmj.j3522). For over a decade the European Working Time Directive has mandated that doctors get at least 11 hours' rest a day; but doctors in other countries, such as the US, work longer shifts.

Speaking in favour of 24 hour shifts, Steven Stain argues that no evidence has shown them to be harmful to patients and that they may encourage continuity. Evidence is, however, limited.
A recent non-inferiority trial suggests that 24 hour shifts do not adversely affect outcomes among surgical patients when compared with 16 hour shifts. And no conclusive evidence shows an impact on patient safety and medical error more broadly.

In the counterargument, Michael Farquhar describes how sleep deprivation is a known cause of burnout and therefore a compelling reason against longer shifts. Doctors are no different from other people in their need for regular sleep, he says, and to encourage longer shifts would perpetuate the myth that doctors are superhuman and would ignore the potentially harmful side effects of fatigue and exhaustion.

Where, then, do the solutions to burnout lie? Oliver is clear that a focus on individual resilience can shift responsibility for burnout away from systems and not tackle the root causes-a view shared by editorialists Lemaire and Wallace, who urge that professional bodies and healthcare organisations must consider the improvement of doctors' wellbeing and working lives as central to patient care. While individually targeted interventions can make a small difference, only a concerted, system level approach will deal with system level causes.

1 Psirides A. Tweet—A better definition of burnout I have yet to read. 12 Jul 2017. https:// twitter.com/psirides/status/885069967871410179.Psirides

Published by the BMJ Publishing Group Limited. For permission to use (where not already granted under a licence) please go to http://group.bmj.com/group/rights-licensing/ permissions 